\title{
Pre-operative diagnosis of ovarian ectopic pregnancy: a challenge to practicing clinician
}

\author{
Shalini Mahana Valecha, Dolly Bashani*, Jaya Gedam, Pandeeswari
}

Department of Obstetrics and Gynecology, ESI-PGIMSR, Mumbai, Maharashtra, India

Received: 07 December 2018

Accepted: 07 February 2019

*Correspondence:

Dr. Dolly Bashani,

E-mail: dollybashani91@gmail.com

Copyright: (C) the author(s), publisher and licensee Medip Academy. This is an open-access article distributed under the terms of the Creative Commons Attribution Non-Commercial License, which permits unrestricted non-commercial use, distribution, and reproduction in any medium, provided the original work is properly cited.

\begin{abstract}
The first case of primary ovarian ectopic pregnancy was reported by St. Maurice in 1689. Primary ovarian ectopic pregnancy is rare entity, with incidence of around 3\% of all ectopic pregnancies. The aim of present case report is to study the role of different modalities like clinical findings, biochemistry, sonography, surgery and histopathology in diagnosis of primary ovarian ectopic pregnancy. Authors present a case of a 24 years old female with history of 2 months amenorrhoea, per vaginal spotting and mild intermittent abdominal pain in RIF. Examination was unremarkable and serum $\beta$ HCG was $2007.5 \mathrm{IU} / \mathrm{ml}$. An ultrasound scan showed an ectopic mass in the right adnexa suggestive of a tubal ectopic pregnancy and she underwent surgical management at our institute. At laparoscopy, both fallopian tubes were noted to be normal with an ectopic mass attached to the right ovary with a pedicle. With these unusual laparoscopic findings, possibilities of tubal miscarriage, ovarian pregnancy, or abdominal pregnancy were suspected. Ectopic mass was coagulated and cut through the pedicle with bipolar cautery and specimen was sent for HPE. Our patient made an uneventful recovery and no further medical management was indicated. The diagnosis of right ovarian ectopic pregnancy was finally confirmed by histopathological evidence of the presence of chorionic villi in a background of ovarian stromal tissue, in consideration with Spigelberg's criteria. Present case highlights the importance of considering non-tubal ectopic pregnancies when making a diagnosis based on ultrasound scan. Preoperative diagnosis of ovarian ectopic pregnancy still remains a challenge in spite of current medical advances. Despite the benefits and reliability of ultrasound scanning, there will still be situations where the definitive diagnosis can only be made at surgery. However, histopathological examination is confirmatory and always mandatory.
\end{abstract}

Keywords: Amenorrhoea, Laparoscopy, Primary ovarian pregnancy

\section{INTRODUCTION}

An ectopic pregnancy is when the implantation and development of embryo occurs outside the uterine cavity like in fallopian tube, cervix, ovary, abdomen or previous caesarean scar. ${ }^{1}$ Ovarian pregnancy is a rare form of ectopic pregnancy, but it is the most common type of non-tubal ectopic pregnancy. ${ }^{2}$ The incidence of ectopic pregnancies is $1-2 \%$ of all pregnancies and location in the ovary, is $3 \%$ of all ectopic pregnancies. The incidence has been reported to be about $1: 7000$ to $1: 40000 .^{3}$
Ovarian ectopic pregnancy is a condition that can endanger the life of a woman, if it is not diagnosed early and managed actively. An untreated ovarian pregnancy can cause potentially fatal intra-abdominal bleeding and thus leading to shock. It is one of the most common gynaecological emergencies, a major cause of maternal morbidity and accounts for $10-15 \%$ of maternal demise, with the reduction in case fatality rates over the years. ${ }^{4,5}$

Amenorrhoea, abdominal pain, vaginal bleeding are the classical symptoms found in ectopic pregnancies. Pain is 
one of the most common symptoms which varies with severity and nature of the cases. Traditional risk factors for ovarian ectopic pregnancy are intrauterine device, pelvic inflammatory diseases, and ovulatory drugs and assisted reproductive techniques. It must be noted, however, that it can occur in the absence of any antecedent risk factor. ${ }^{6}$

Preoperative diagnosis is challenging, but ultrasound, especially transvaginal scanning is helpful in diagnosis.

Diagnostic delay may lead to a rupture, secondary implantation, operative difficulties and maternal death; therefore, awareness of this rare condition is important in reducing the associated morbidities.

Diagnosis is based on surgical and histopathological observations and it continues to challenge the practising clinician. Authors report a case of primary ovarian pregnancy presenting with unusual laparoscopic findings.

\section{CASE REPORT}

A 24 years old female Gravida 2 MTP 1 came to O.P.D. with history of 2 months amenorrhoea, per vagina spotting for 3 days and mild intermittent abdominal pain on right side and bloating sensation for 2 days. Her previous menstrual cycles were regular, painless with moderate flow.

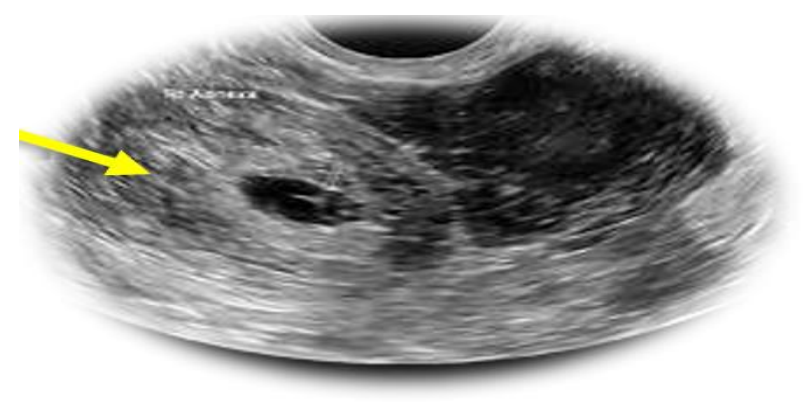

Figure 1: Ultrasound picture showing right adnexal mass.

Obstetric history is MTP done one year back with MTP pills, no check curettage done. There was no significant past medical or surgical history or history of any previous ectopic pregnancy, IUCD insertion, or assisted reproductive techniques. On examination, patient had moderate pallor, vitally stable with pulse $90 / \mathrm{min}$, BP 100/70mmhg. On per abdomen examination, mild tenderness could be elicited in right iliac fossa. On per vaginum examination, uterus is anteverted, bulky with right sided forniceal fullness and minimal cervical motion tenderness.

Count $2.36 \mathrm{l} / \mathrm{mm} 3$, beta HCG level was $2007.5 \mathrm{IU} / \mathrm{ml}$ (on admission) and USG findings suggestive of right adnexal mass with increased vascularity, $\mathrm{B} / \mathrm{L}$ ovaries appeared normal, most likely right sided tubal ectopic pregnancy of 5.4 weeks gestation. No free fluid.

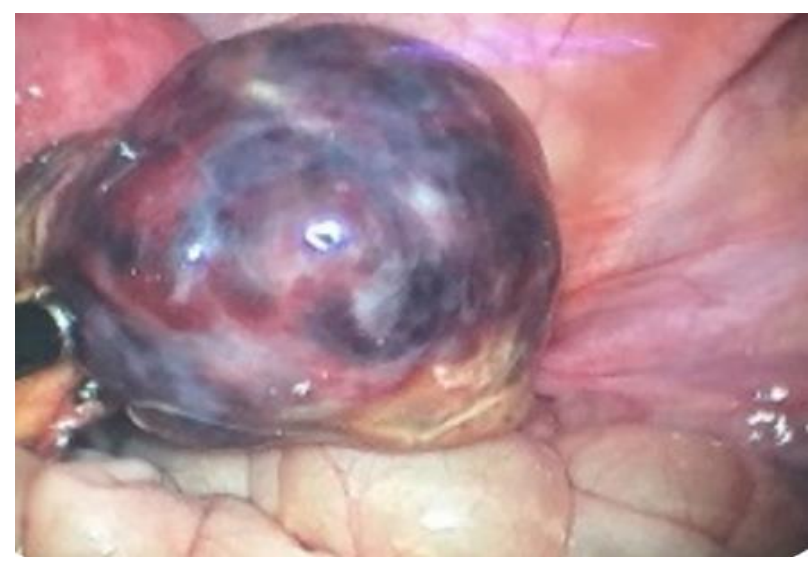

Figure 2: Ovarian ectopic mass.

On investigations, urine pregnancy test is positive, complete blood count done with Haemoglobin $9.2 \mathrm{mg} / \mathrm{dl}$, platelet count $2.36 \mathrm{1} / \mathrm{mm}^{3}$, beta HCG level was 2007.5IU/ml (on admission) and USG findings suggestive of right adnexal mass with increased vascularity, B/L ovaries appeared normal, most likely right sided tubal ectopic pregnancy of 5.4 weeks gestation. No free fluid. Patient was haemodynamically stable. After 48 hours, repeat beta HCG levels were $2315 \mathrm{IU} / \mathrm{ml}$.

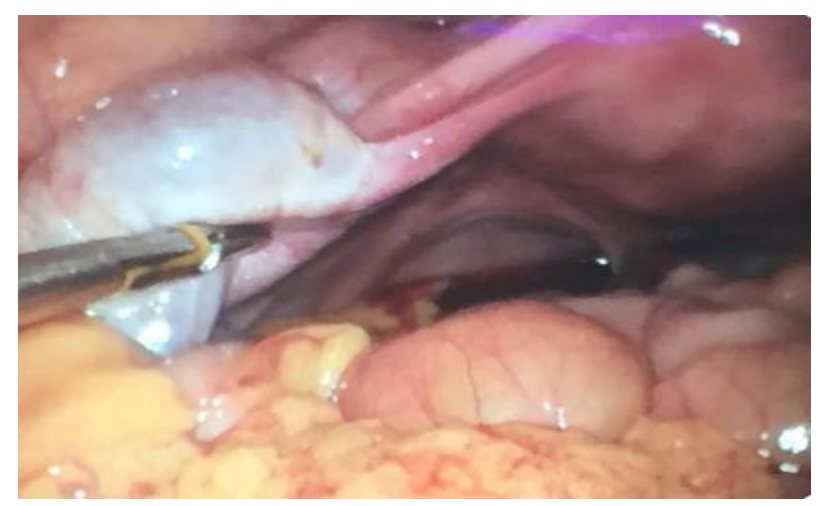

Figure 3: Left ovary.

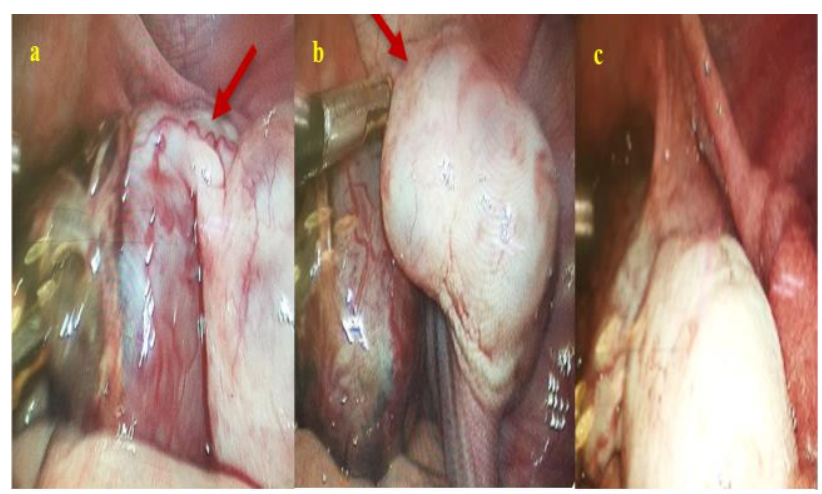

Figure 4: Ectopic mass attached to ovary with pedicle. 
Operative laparoscopy was done with intra operative findings of right sided mass of about $4 \times 4 \mathrm{~cm}$ seen attached to right ovary with a pedicle, left sided ovary appeared bulky. B/L fallopian tubes appeared intact and normal and no haemoperitonium noted.

Excision of ectopic mass was done by coagulating and cutting the pedicle and specimen was sent for histopathology.

Histopathological examination revealed the presence of chorionic villi with presence of ovarian stromal tissue in background. Thus, according to Spigelberg's criteria for ovarian ectopic, the diagnosis of unruptured ovarian ectopic pregnancy was made.

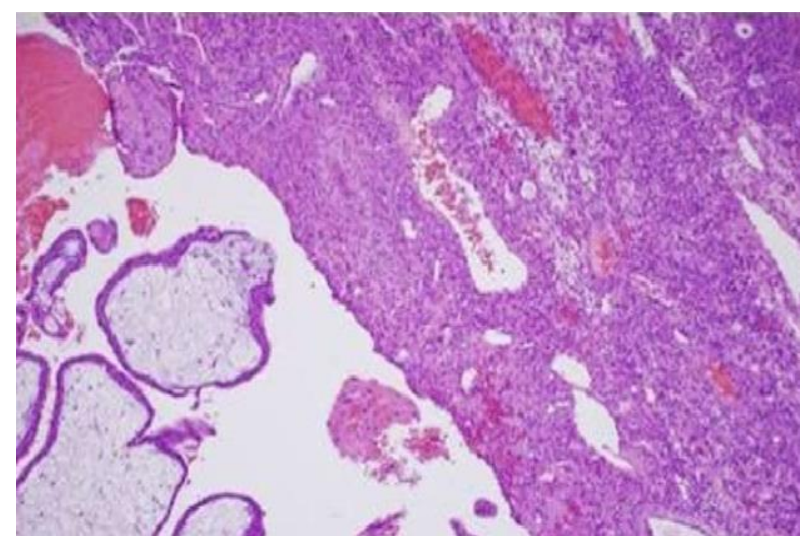

Figure 5: Histopathological picture showing degenerated chorionic villi with ovarian stromal tissue.

\section{DISCUSSION}

The first case of primary ovarian ectopic pregnancy was reported by St. Maurice in 1689.,8 Ovarian ectopic pregnancy is an uncommon form of all ectopic pregnancies. Incidence is one in 7000-40,000 pregnancies. It can be a primary ovarian pregnancy or secondary to a ruptured tubal pregnancy. Cause of ovarian pregnancy remains unknown but as per some hypothesis, reflux of the conceptus following a normal fertilization from the uterus, failure to release ovum from ruptured follicle, altered tubal motility and also the inflammatory thickening of tunica albugenia may be the reasons of ovarian implantation. ${ }^{9}$

Ovulatory medication assisted reproductive techniques, pelvic inflammatory disease, intrauterine device, endometriosis are few risk factors that are strongly associated with ovarian ectopic pregnancy. ${ }^{6}$ But it may also occur without any antecedent risk factors. ${ }^{10}$ Lehfeldt et al, in his study stated that contraceptive IUD prevents intrauterine implantation in $99.5 \%$, tubal implantation in $95 \%$ and none at all in ovary. ${ }^{11}$ And also, only a few cases of ovarian pregnancy following tubal ligation have been reported as per the literature survey. ${ }^{12}$
Our case presented with the classical symptoms of amenorrhoea, bleeding per vaginum and pain in abdomen. Due to low incidence, clinical suspicion of ovarian ectopic pregnancy tends to be low. Other conditions like tubal pregnancy, ruptured haemorrhagic corpus luteal cyst, torsion of ovary or chocolate cyst can also present similarly. ${ }^{13}$ Diagnosis of ectopic pregnancy can often be made on the basis of history, clinical presentation, serum beta-HCG level and pelvic ultrasonography. But it has been reported that quantitative $\beta \mathrm{HCG}$ level may be unreliable predictor and ultrasound examination may be misleading as there is no evidence based diagnostic criteria of ovarian pregnancy on ultrasonography.

In present case, laparoscopic findings raised the suspicion of abortion of tubal ectopic (tubal miscarriage), ovarian pregnancy, secondary abdominal pregnancy. Diagnosis of ovarian ectopic was made on the basis of criteria of Spigelberg: the fallopian tube on the affected side must be intact, the foetal sac must occupy the position of ovary, the ovary must be connected to the uterus by the ovarian ligament, ovarian tissue must be located in the sac wall. ${ }^{14}$

Management of ovarian pregnancy is usually surgical, as maximum patients present late with profuse bleeding, shock and diagnosis is made intraoperatively. Most preferred surgery is partial oophorectomy or cystectomy by either laparotomy or laparoscopy. ${ }^{15}$ Laparoscopy with ovarian sparing in the stable woman is today the surgical treatment of choice. ${ }^{16}$ Sometimes, oophorectomy may be suggested.

The alternative treatment especially for unruptured ovarian pregnancy is methotrexate therapy but under strict supervision. Systemic methotrexate can be used to treat ovarian ectopic pregnancy when the risk of surgery is high, or postoperatively in the presence of persistent residual trophoblast or persistently raised b-HCG levels. ${ }^{17,18}$

\section{CONCLUSION}

The diagnosis of primary ovarian pregnancy continues to challenge clinicians. It should be entertained as one of the important differential diagnosis in a female of reproductive age group with a history of amenorrhea of short duration. Whenever suspicion arises, serum beta HCG estimation and transvaginal ultrasound by an experienced sonologist can help in the diagnosis. Laparoscopy is gold standard in these cases, both for diagnosis and treatment. However, histopathological examination is confirmatory and always mandatory.

Though rare among ectopic sites, ovarian implantation has increased risk of life-threatening condition as the ovaries have dual blood supply and due to such high vascularity, rupture of ectopic sac will exsanguinate the patient quickly. A strong index of suspicion is required to ensure timely diagnosis and prompt treatment. 
Funding: No funding sources

Conflict of interest: None declared

Ethical approval: Not required

\section{REFERENCES}

1. Choudhury S, Devi GP, Devi PP. Ovarian Ectopic Pregnancy: A Case Report.2015;14(11):40-42.

2. Begum J, Pallavee P, Samal S. Diagnostic dilemma in ovarian pregnancy: a case series. J Clin Diagn Res. 2015;9(4): QR01-3.

3. Álvarez-Goris MP, Mendoza-Moreno JM, Sánchez Zamora R, Torres-Rivera RA, Galicia-Pedraza AK. Ectopic ovarian pregnancy with little common clinical presentation. Case report and review of the bibliography. Mex J of Obstet Gynaecol. 2015; 83(9): 545-0.

4. Leke RJ, Goyaux N, Matsuda T, Thonneau PF. Ectopic pregnancy in Africa: A population-based study. Obstet Gynecol. 2004;103:692-7.

5. Farquhar CM. Ectopic pregnancy. Lancet 2005;366:583 91 .

6. Kraemer B, Kraemer E, Guengoer E, Juhasz IB, Solomayer EF, Wallwiener D et al Ovarian ectopic pregnancy: diagnosis, treatment and correlation to Carnegie stage 16 and a review based on a clinical case. Fertil Steril 2009;92(1):13-5.

7. Ogunbode OO, Aremu OO, Okolo CA. Premary ovarian pregnancy mimicking abdominal pregnancy. Niger Postgrad Med J. 2015;22:185-8

8. Prabhala S, Krukkambattu J, Dogiparthi A, Kumar P, Tanikella R. Ruptured ovarian pregnancy in primigravida. Int J Appl Basic Med Res.2015;5(2).

9. Nicholas FK, Schwartz LB. Primary ovarian pregnancy successfully treated with methotrexate. Am J of Obstet Gynaecol.1992;167(5):1307-8.

10. Roy J, Sinha Babu A. Ovarian pregnancy: Two case reports. Australas Med J. 2013;6(8):406-14.
11. Lehfeldt H, Tietze C, Gorstein F. Ovarian pregnancy and intrauterine device. Am J Obstet Gynecol. 1970;108:1005-09.

12. Vahnu C, Rajlaxmi M, Vandana R. Primary Ovarian Pregnancy after Interval Tubal Ligation: A Case Report J Family Reproduct Health.2013;7(4).

13. Chelmow D, Gates E, Penzias AS. Laparoscopic diagnosis and methotrexate treatment of an ovarian pregnancy: a case report. Fertil Steril. 1994;62:87981.

14. Scutiero G, Di Gioia P, Spada A, Greco P. Primary ovarian pregnancy and its management. JSLS 2012;16(3):492-4.

15. S Nadarajah, LN Sim, SF Loh. Laparoscopic management of an ovarian pregnancy Singapore. Med J. 2002; 43(2):095-096.

16. RJ Joseph, LM Irvine. Ovarian ectopic pregnancy: Aetiology, diagnosis, and challenges in surgical management. J Obstetr Gynaecol.2012; 32(5).

17. Wen-Hsiang Su, Sai-Ming Cheung, Sheng-Ping Chang, Wen-Hsun Chang, Ming-Huei Cheng.Is ovarian pregnancy a medical illness? methotrexate treatment failure and rescue by laparoscopic removal Taiwan. J Obstet Gynecol. 2008;47(4).

18. Elson CJ, Salim R, Potdar N, Chetty M, Ross JA, Kirk EJ. On behalf of the Royal College of obstetricians and gynecologists. Diagnosis and management of ectopic pregnancy. BJOG. 2016;123:e15-e55.

Cite this article as: Valecha SM, Bashani D, Gedam J, Pandeeswari. Pre-operative diagnosis of ovarian ectopic pregnancy: a challenge to practicing clinician. Int J Reprod Contracept Obstet Gynecol 2019;8:1193-6. 